\title{
Information security of educational environments of school
}

\author{
Elena N. Dzyatkovskaya ${ }^{1,3,}$, and Nina Tsvetkova ${ }^{2}$ \\ ${ }^{1}$ ISED RAE, Laboratory of General Issues of Didactics, 105062, Moscow, Russia \\ ${ }^{2}$ MSU, UNESCO Chair, Moscow, Russia \\ ${ }^{3}$ RAS, Scientific Center for Family Health Problems and Human Reproduction, 664003, Irkutsk, Russia
}

\begin{abstract}
The information as an important ecological factor, which defines the security, development and health of children is considered. The article raises the problem of distortion of the information environment of childhood in the post-industrial era. The aim is to ensure information security educational environment for all participants in the educational process. It is proved that the hygienic approach to solving problems is insufficient. Adaptive-developing strategy for information security of the educational environments for children was theoretically justified and proved by the practical results of medical, physiological and neuropsychological research. It provides the school work on the compensation of violations of the information environment of childhood; development resources of students' resistance to information stress; expanding the sphere of their adaptation to the information load (adaptive norm); the principles and structure of management of educational process on the basis of system-wide control of complex, self-regulating systems.
\end{abstract}

The information in the $21^{\text {st }}$ century is being transformed into a new, important ecological factor. In the rapidly changing information environment social, medical, moral, ethical, legal and military problems of human, society and nature security are sharply marked.

Due to anthropogenic changes in the environment rapid process of loss of biological information on the planet is so great that has no analog in history.

The process is accompanied by deterioration in the quality of the remaining information, the accumulation of genetic load in it.

The problem of loss of ethno-cultural information (language, folklore, way of life), especially of small Nations have been aggravated under the onslaught of civilization. At the same time, both the volume and quality of social information is changing rapidly like an avalanche.

It's doubling occurs every two years. The share of the information trash, aggressive information, distorting the semantics of the basic human values is growing rapidly. State, society, economy, individuals become the subject of media attacks.

In all countries quick changes of evolutionary tested information environment of humankind leads to growth of psychosomatic disorders - information neuroses and their somatic equivalents, which are manifested in violations of the regulation of internal organs.

They are called "information illnesses" (by N. G. Kryzhanovskii) [1]. Chronic fatigue syndrome is becoming more common in the world. The state of psychological fatigue, depression becomes typical for large masses of the population.
Dissemination and rejuvenation of the neuroses, vascular dystonia, hypertension, allergies, disorders of the reproductive sphere is registered in child populations [2]. The occurrence of these pathologies in pediatric populations increases from $20 \%$ in pre-school age up to $60-80 \%$ by the completion of the school and becomes the cause of more than $80 \%$ diseases of adults. The diseases of the nervous regulation are the cause of reduction of resources adaptation to information load.

Features of the information environment of a child's development could induce information pathology of schoolchildren. A number of studies, including our own (the Clinic of Pediatrics and Institute of Human Reproduction of the Russian Academy of Medical Sciences) have demonstrated that one of the reasons is a violation of the natural-social environment, which is necessary for all stages of the full development of the child: the parent, natural (up to 2 years), mythological (to 5 years), ethical (to 8 years).

Violation of emotional contact with the mother at an early age (maternal deprivation which occurs today even in two-parent families), the scarcity of natural information in the child's environment (natural sounds, smells, materials...), lack of meaningful archetypal ethno-functional information (folk tales, games, lullabies...) on the background of congenital neurological problems contribute to risk of psychosomatic disorders development at school age.

Such children have reduced physiological resources, psychological and psycho-social resources of adaptation to school. Their nervous system is vulnerable to increased training load including work with computers.

\footnotetext{
Corresponding author: dziatkovskaya@mail.ru
} 
Starting at school, they become a risk group on development of nervous regulation diseases in primary school, and since 12 years - on the formation of different types of addictions (including drug and Internet), suicidal risk, social disadaptation [3].

Formation of information security culture among all participants of the educational process is the most important task of the educational environment. It is of global importance in the information society.

The modern world realities encourage the education system to reflect its place and role in the emerging information society, its contribution to the information security of the younger generation.

Attempts to operate using restrictive measures appear insufficient.

Every day new information risks appear for human life. It is difficult even to predict them. However, the safety of human life is ensured not by riskless environment, but, above all, by ability to adjust risk, to manage them. Therefore, the problem of education in ensuring the human right to security of their information environment appears today in the forefront.

Innovations envisaged in the standard of education of the second generation offer a constructive solution to the problem of formation of pupils' culture of information security.

On the one hand, there are federal programs of education and socialization, which create the value of human rights to a safe environment.

On the other hand, the documents of the standard include the program of development of universal educational actions - as an instrumental basis for safe work with information.

Such skills are an essential prerequisite of common cultural competence of the person. Learning to learn - is their part. It involves a person's ability to ensure the information security of their studies in childhood and in adulthood, the ability to learn throughout life. These skills are provided by global education - education for sustainable development.

Information security of human being is achieved, above all, by his skills and ability to regulate the quantity and quality of consumed and produced information based on the values of human health and the environment.

The instrument of formation of this competence is a learning activity - student's work with training information.

The problem of the information environment security for students is not new in comprehensive and high school. However, it is often limited to the discussion of issues of sanitation, hygiene and physical culture.

Usually the control of the security activities of educational institutions is regulated by standard requirements of Sanitary regulations.

These requirements relate to light, heat, epidemiological conditions of the educational process, the mode of training load (volume, types, distribution by days of the week and during the day), balancing teaching load with the help of large and small forms of physical education.
Teachers also discuss the psychological climate of relationships between teachers, students and their families.

Without diminishing the importance of these security aspects of the educational process, we believe that this approach ignores information security of educational environments.

This problem can be considered from several positions.

Firstly, we are talking about correction of the childhood information environment in primary school so as to compensate the problems of psycho-physiological and psycho-social development of children in preschool age. Prevention of different kinds of deprivations (emotional, sensory, cognitive, social) as well as overcoming pupils' ethno-functional dissociation is provided.

Secondly, it is necessary to provide for psychological and pedagogical quality of training exercises, training material, and means of education. The training texts should not have formal logical fallacies and contradictions, the subject content must be continuous, consistent, integrated with interdisciplinary methods of study, meta-language, etc.

Thirdly, the content of the student's educational activity should take account of its zone of proximal development, include the divergent methods and techniques of teaching, training them, creation the ability to choose / create adequate strategies of cognitive activity and its psychological and pedagogical conditions; contribute to the formation of rational individual learning style and its organizing, etc. [4].

Fourthly, we speak about a model of bioadequate management of educational process, which should not lead to a conflict between social control and selfregulation of self-organizing systems included in the educational environment (we call this condition "environmental imperative in pedagogy").

We believe that the task of building a culture of information security in educational environments is much wider than just training on the use of modern computer technology.

Information security culture is considered as the part of the learning culture in the information society. This is a safe use of information products, an ability to create secure intellectual products (professional and educational), a respect for intellectual property, etc. This is the consciousness, which is rooted in the intangible cultural heritage of society, it is civil global and national identity of a person.

We applied the integrated medical-psychologicalpedagogical approach when we examined ways of ensuring the information security of schoolchildren in the large group of leading scientists (Russian Academy of Medical Sciences and the Russian Academy of Education). Such approach was provided by the general object of study, exposure, correction and prevention for different professionals (neuropsychologists, physiologists, physicians, educators). This object is the central regulatory systems of children (body/personal), which determine functional systems of his cognitive activity. 
In this case we distinguish the influence of information and informational hardware, emotional stress and information stress on the child. We have investigated the mechanisms of information stress of students (information triad, by M. M. Khananashvili) and identified the risk group for prevention of psychosomatic disorders; cleared up key approaches to improve children's resistance to educational stress; studied the contribution of educational content to the formation of informational security culture.

Our hypothesis is that informational stress prevention is not limited to the specific methods of work with ICT, tools of informatization, the Internet, and is, above all, non-specific in nature.

We relied on the fundamental concepts of the physiology about the capacity of the neuropsychiatric regulation (levels of voluntary and involuntary regulation) to ensure resistance to stress and when compensatory possibilities are exhaustive - to adapt, which prevents the development of chronic stress status [5].

We took into account that the development of neuropsychiatric regulations of the child is the resultant of information processes in environmental systems of various nature (biological, social, artificial) that act through the implementation of congenital programs of child development, learning and teaching.

The maturity of neuropsychiatric regulations of the child is not only the result, but also the base for ensuring its information security needs. In the development of neuropsychiatric regulations in childhood the systemically important role belongs to the leading activity.

Therefore, the purposeful formation of students' individual resources of self-regulation in emotional, motor, cognitive, personal and social spheres becomes relevant.

The resource-based approach to the prevention of chronic informational stress gives you the opportunity not to depart from loads of information, but rather to increase the accessibility of cultural heritage to children.

In this study, we used objective indicators of the development of information stress and information pathologies, including electrophysiological, clinical, laboratory, functional, psychological indicators, which were described in detail in several monographs.

These studies marked the beginning of a new trend in psychosomatic medicine and health saving pedagogy of children's age, based on system-wide principles on the management of self-regulating systems. Today this direction is developing in the Russian Academy of Medical Sciences and implemented in practical health care and education.

The results were used to develop a model of organization of educational process, ensuring the prevention of diseases of the nervous regulation with obtaining a clinically significant effect. This is consistent with the principle of "education for all" and contributes to the growth of the education quality.

Comprehensive studies have shown that prevention of diseases of the nervous regulation - the task is no longer medical, and pedagogical. Key directions of its decision: compensating for impaired information environment of childhood; the development of students' resources of resistance to information stress and the expansion of the boundaries of adaptation to the information loads (adaptive norm); the principles and structure of management of educational process on the basis of system-wide control of complex, self-regulating systems.

The formation of safe educational information environment involves the development of students' resources of resistance to information stress and pushing the limits of adaptation to information load through education.

It has been proven that the development of the information stress does not depend on individualtypological peculiarities of the perception, processing, transformation of information, memorization, etc., but individually determined by the presence of weak links (vegetative, emotional, cognitive, motivational, volitional, communicative) in the functional system of regulation of learning, which are identified in the process information using objective criteria.

Information stress when it has systematic repetition leads to "breach" in the system of regulations of the child, which significantly reduces the functionality of the nervous system to withstand and adapt to new environmental conditions. Criteria and indicators the selection of schoolchildren's risk groups of the development of information pathologies were determined.

Clinical studies have proven that prevention of "breach" in the regulation of the child's educational system lies in the pedagogical plane. So the risk control of developing chronic stress information related not only to arbitrary, but an involuntary regulation, requires changes not only in the content of education, but also the organization of the educational process [6].

Psycho-pedagogical program aimed at changes in lifestyle child, family upbringing, communication, as well as play, physical and mental exercises aimed at training resources regulation and increasing resistance to information stress have been developed, clinically tested for schoolchildren as tools of nonspecific prevention of information pathologies development.

The use of these exercises provides with a help of systematic efforts, but does not require special skills and is available for parents without special training. Children's folk games, specially selected physical exercises, having a game character, certain ways of working with information (e.g., the use of images, metaphors), etc. are actively used in such programs.

Significant changes were made to the organization of the whole educational space, its principles of management have a bio adequate nature and are aimed at preventing managerial stress.

For extracurricular activities methodical complex of a preventive orientation "Ecology of learning activities" was developed ("Learning to learn" - for elementary school, "Learning to communicate" for basic school, "Learning to be an adult" for high school). Lessons simulate problem situations working with educational and non-educational information, communication, 
promote application of universal educational actions in situations of information risks.

Ideas about the adaptive nature of a healthy lifestyle, as well as resources for successful learning - biological, emotional, intellectual, volitional, communicative are formed on the basis of ecological cognitive model.

The knowledge about peculiarities of healthy lifestyle in different information environment lays the foundation of healthy academic culture.

The developed training materials have an educational focus on the formation of ethical, patriotic, ecological, humanistic values, the values of the natural and cultural information, cultural traditions of different peoples of Russia, identity in the culture and the natural world and inter-ethnic tolerance.

The idea of responsibility of each person for the protection of unique biological and cultural information environment on the planet by monitoring his activity in the production sphere, transformation and distribution of the information is a priority.

Security problem of the information environment is considered with emphasis on the unique role of information in the conservation of life on Earth.

A variety of non-material cultural and ethno-cultural information, as a valuable heritage of civilization, is regarded as a means of preserving the biological variety on the planet. Experience of secure personal learning environment; risk control and bio adequate control is formed.

In primary school, the selection of exercises are aimed at:

compensation sensory and emotional deprivation of the child (schoolchildren are experimenting with sounds, colors, shapes, surfaces, movement, emotions and so on, their diversity);

ensuring ethno-functional adaptation of students (with parents); forming of self-learning methods;

formation of the primary experience of creating of safe educational environment.

In secondary school, the central tools of students' information security are strategies of training and individual learning style.

The prolonged studies (from 1 to 11 form, 536 schoolchildren of risk group, for 15 years) have presented that such strategy of information security allows to prevent the development of psychosomatic disorders; to form a healthy lifestyle adaptive to modern information environment; to lay the foundations of healthy academic culture [7].

\section{References}

1. G.N. Kryizhanovskii, Determinantnye strukturi $v$ patologii nervnoy sistemyi (Meditsina, Moscow, 1980) [In Rus]

2. A. V. Suharev, Psiholog. Zhurnal, 17(3), 129-136 (1997)

3. E.N. Dzyatkovskaya, L.I. Kolesnikova, V.V. Dolgih, Informatsionnoe prostranstvo $i$ zdorove shkolnikov (Nauka, Novosibirsk, 2002) [In Rus]

4. A.A. Pligin, World of Psychology, 4 (2007).

5. K.V. Sudakov, Emotional stress (NII im. P.K. Anohina, Moscow, 1992) [In Rus]

6. L.I. Kolesnikova, E.N. Dzyatkovskaya, V.V. Dolgih, Adaptivno-razvivayuschaya strategiya sohraneniya zdorovya shkolnikov (Litterra, Moscow, 2015) [In Rus]

7. L. Kolesnikova, E. Dzyatkovskaya, L. Rychkova, Social and Behavioral Sciences, 214 (2015) [In Rus] 